\title{
Increased copulation duration does not necessarily reflect a proportional increase in the number of transferred spermatozoa
}

\author{
Tom A. Weggelaar, Daniël Commandeur and Joris M. Koene* \\ Department of Ecological Science, Faculty of Sciences, Vrije Universiteit Amsterdam, \\ The Netherlands
}

Submitted: July 19, 2018. Final revision received: October 11, 2018. Accepted: November 15, 2018

\begin{abstract}
Post-copulatory sexual selection research tends to focus on the numerous adaptations that have evolved to increase the chances of donated spermatozoa fertilizing oocytes. Even though fertilization obviously directly depends on the presence of sufficient, viable spermatozoa, the quantification of the sperm transfer process itself has not received the attention it deserves. Here, we present experimental work on a simultaneously hermaphroditic snail in combination with a review of the literature focussing on the relationship between the duration of copulation and the number of sperm that are transferred. Based on classical work, this relationship is often assumed to be linear, but as we show here this need not be the case. Both our experimental data and the reviewed literature indicate that there are clear instances where the process of sperm transfer is not a linear process, i.e., longer copulation duration does not necessarily imply more transfer of sperm. As we point out, there seems to be a bias in the literature towards investigating this in insects, but other animal groups in which this has been investigated do show similar relationships. To conclude, we discuss how the specific patterns of sperm transfer that have been reported can be biologically interpreted and we caution that simply using copulation duration as a proxy for the number of sperm transferred can be misleading.
\end{abstract}

\section{Keywords}

Copulating; crustacean; gamete; insect; mating; mollusc; reptile; snail; spider

\section{Introduction}

Sexual selection is a major evolutionary driving force and has led to numerous adaptations aimed at increasing the chances of donated sperm reaching the ripe

*) Corresponding author; e-mail: joris.koene@vu.nl 
eggs for fertilization. This directional selection finds its origin in anisogamy, i.e., the difference in size between the two types of gamete, large eggs and small sperm (e.g., Schärer et al., 2012). Because the female sex usually invests more per egg than males do per sperm, this often results in females that are selective about with whom, how often and with how many partners to mate, with the ultimate aim to produce a limited set of offspring with high fitness (Bateman, 1948). In contrast, sperm are generally thought to be energetically much less costly. Therefore, in many species males are capable of mating with many partners and can aim to maximise the number of eggs they fertilise. As a result, even though every male in a population will attempt to mate as often as possible, the number of females that are willing and/or able to mate will become the limiting factor (Bateman, 1948). Under such circumstances, to which there are of course exceptions, males have been selected to evolve all kinds of strategies that are aimed at gaining an advantage over the other sperm-donating competitors in the population, which are all competing for fertilisation of the same finite set of eggs (Parker, 1970).

Evolved strategies are usually divided into those that occur prior to sperm transfer and those that occur afterwards. The former, referred to as pre-copulatory sexual selection, encompasses mate choice and male-male competition, which were the main focus of Darwin's seminal book (Darwin, 1871). Essentially, this underlies the evolution of extravagant looks and ornaments of males, such as those found in birds of paradise (e.g., Scholes \& Laman, 2018), as well as armaments and seemingly odd behaviours, such as those seen in horned beetles (e.g., McCullough et al., 2018) and sandcastle-building fish (Magalhaes et al., 2017), Moreover, as has become clear over the past decades, especially thanks to the pivotal insights of Parker (e.g., 1970), sexual selection does not stop when sperm have been transferred. At this stage of the reproductive process, sperm competition and cryptic female choice come into play (e.g., Parker, 1970; Eberhard, 1996, respectively). These post-copulatory sexual selection processes have received a lot of attention in recent years, especially in internally-fertilising species. This has led to the realisation that females often mate with more than one sperm donor and that those females are able to store the sperm of different donors in specialised organs (e.g., Parker, 1970). As a result, so-called cryptic female choice can potentially occur inside the female reproductive tract resulting in selection for sperm of the 'best' donor for fertilising the available eggs (Eberhard, 1996).

While sperm competition and cryptic female choice are notoriously hard to disentangle, and may sometimes (appear to) be sides of the same coin, they both enhance selection on post-copulatory processes. This leads to a rather cryptic evolutionary arms race between male and female interests where the transfer of accessory gland proteins, and resistance against their effects, seems to play a central role (e.g., Koene, 2017; Lodi \& Koene, 2017; Alvarez \& Koene, 2019). And while the latter has received much attention in recent studies, the role of the sperm transfer process itself (i.e., the gametes themselves) seems to have received less attention than it 
deserves. Of course, there are the obvious examples of male damselflies and cuttlefish that have evolved specialised organs that they use, prior to inseminating the female, to remove rival sperm that she already has stored in her reproductive tract from previous inseminations (e.g., Wada et al., 2010; Cordero-Rivera, 2016). Other strategies that are frequently encountered in the animal kingdom are the inhibition of remating either via chemical or physical means, such as via copulatory plugs, mate guarding and frequent copulation (e.g., Birkhead \& Møller, 1992; Simmons, 2001; Brown \& Baer, 2005).

All of these examples somehow influence the number of sperm (compared to those from competitors) that are present in the female reproductive system and emphasise that a sperm cell itself is of course the ingredient of copulation that is required for successful fertilisation (Birkhead \& Møller, 1992; Birkhead et al., 2009). Parker's definition of sperm competition as being 'the competition within a single female between the sperm from two or more males over the fertilization of the ova' has also led to many predictions about how males should strategically allocate their sperm depending on sperm competition risk and intensity (e.g., Wedell et al., 2002; Parker \& Pizzari, 2010; Kelly \& Jennions, 2011). Yet, relatively little consideration seems to be have been given to how sperm are transferred within a single copulation. One textbook example that considered this process is the research done by Thornhill (1976) on hanging flies (Bittacus apicalis Hagen, 1861). In that study a male provides its mating partner with a nuptial gift, a prey item that the female consumes during copulation. The size of the prey item determines how long copulation lasts and, by counting sperm, Thornhill was able to show that this copulation duration reflects the number of sperm that are transferred. In other words, with an increase in copulation duration the number of sperm transferred increased in a linear fashion reaching a maximum after 20 to 21 minutes (Thornhill, 1976).

This relationship is very intuitive and as a result many studies have assumed that copulation duration provides a proxy that reflects the number of sperm transferred. For some purposes, such as assessing the generality of strategic sperm allocation, such proxies can be useful (e.g., Kelly \& Jennions, 2011). However, they become problematic when the underlying assumption - that the proxy is a good reflection of the number of transferred sperm - has not been verified for the species under study (as also pointed out by Eady \& Brown, 2017). Therefore, in this paper we have a dual aim:

On the one hand, we present data on an experiment done in a freshwater snail - the simultaneous hermaphrodite Lymnaea stagnalis (L.) - testing whether this species transfers sperm in a linear fashion (meaning that an increase in copulation duration leads to a proportional increase in transferred sperm cells), as has generally been assumed to be the case for this species (see below). For clarity, when we refer to copulation duration in the remainder of this paper, we mean the generally accepted definition of the time between the initial insertion of the (male) copulatory organ into the partner's reproductive tract until final withdrawal (i.e., after the complete ejaculate has been transferred; insemination duration). For this particular 
species, the continuous peristalsis of the vas deferens during copulation suggests a constant transport of the ejaculate (Van Duivenboden \& Ter Maat, 1988); in contrast, a previous study found that longer copulations did not result in more sperm transfer (Koene et al., 2008). The present experiment was performed to solve this discrepancy by counting the number of sperm that were transferred to the partner at different time points during copulation.

On the other hand, we provide an overview of published studies that have also specifically tested for the correlation between copulation duration and number of sperm transferred. In doing so, we address which types of relationships are generally found as well as how certain types are distributed across the animal kingdom. In addition, we discuss how these relationships are determined and/or which factors affect and limit them as well as their relevance for post-copulatory sexual selection processes.

\section{Methods}

\section{Sperm transfer experiment}

For this experiment, 440 individuals of the pond snail Lymnaea stagnalis were obtained from our snail breeding facility at the Vrije Universiteit in Amsterdam (The Netherlands). These snails were kept in low-copper, fresh water of $20^{\circ} \mathrm{C}\left( \pm 1^{\circ} \mathrm{C}\right)$, in both the breeding tanks and containers used during the experiment. In the breeding tanks, the snails were raised on biologically-farmed Boston lettuce (Lactuca sativa L.) and fish flakes (Tetraphyll, Tetra GmbH, Melle, Germany). During the experiment, each individual was exclusively fed one circular disc of lettuce (about $19.6 \mathrm{~cm}^{2}$ ) per day. The light:dark cycle was $12: 12$ hours at $5.5 \mathrm{~W} / \mathrm{m}^{2}$.

Sexually mature snails (four months old at the start of the experiment) were randomly selected and isolated, in order to increase their willingness to copulate in the male role (De Boer et al., 1997). Isolated snails were kept in perforated polythene containers $(460 \mathrm{ml})$ for one week. One day prior to the experiment, the snails were placed in clean containers; this stimulates egg laying (e.g., Ter Maat et al., 2012) and decreases egg laying events during the observations on the next day (for which the animals are also placed in a clean container, see below). At the start of the experiment, the shell length of isolated snails was measured $(2.9 \pm 0.2 \mathrm{~cm})$ since this is a reliable indicator of body size (e.g., Koene et al., 2007), and the snails were marked on their shell using a permanent marker (Edding 400 permanent marker Edding, Ahrensburg, Germany) for identification purposes during the observations. Non-isolated snails, from the same age cohort as the isolated snails and with approximately the same shell length were paired with the isolated snails (i.e., pairs were size-matched). These pairs were continuously observed until copulation started. If pairs had not shown interest to mate after six hours, observations of those pairs were terminated and those snails were not reused for the experiment.

For each pair, the time at the start of copulation was noted when the penis had been inserted into the female gonopore and had remained there for $10 \mathrm{~s}$. Copulation, 
which on average takes just over half an hour in this species (e.g., $36 \pm 4$ min: Van Duivenboden \& Ter Maat, 1988), was then either interrupted after 5, 10, 15, 20, 25 or 30 minutes, or not interrupted at all (referred to as completed). These different time points were assigned to each pair prior to the start of the observations on each day, and were randomly divided over the experiment, thus avoiding possible influences of differences between days.

Immediately after the interruption, or completion, of copulation, the transferred ejaculate was collected and the sperm were counted following the protocol by Loose \& Koene (2008; see also Nakadera et al., 2014). In brief, sperm recipients were anesthetized immediately using $2-3 \mathrm{ml} 50 \mathrm{M} \mathrm{MgCl}_{2}$. After the shell was removed with a coarse forceps and the snail was dissected using a fine forceps and surgical (eye) scissors (World Precision Instruments, Inc., Sarasota, FL, USA), the truncus bursae and oviduct were removed and put in an Eppendorf tube. Then, $200 \mu \mathrm{l}$ of Lymnaea saline solution was added and the tissue was crushed using a pair of forceps (World Precision Instruments, Inc., Sarasota, FL, USA). Subsequently, this suspension was vortexed for $30 \mathrm{~s}$. The female tract was moved to a second tube with $200 \mu \mathrm{l}$ saline and vortexed again. This was then repeated once more, after which the contents of the three Eppendorf tubes were mixed together (600 $\mu \mathrm{l}$ in total) and vortexed a final time for $30 \mathrm{~s}$. Note that, if no sperm or a very large amount of sperm was observed (which depended on the time points at which copulation was terminated), we deviated from the standard protocol by, respectively, adding or removing dilution steps. This ranged from one dilution step (200 $\mu \mathrm{l}$ in total) to four dilution steps $(800 \mu \mathrm{l})$ in total, which was necessary to be able to obtain proper estimates of the actual number of sperm present (thus avoiding that low sperm numbers would be counted as zero). When we deviated from the dilution steps, vortex times were adjusted to make sure that each sample was vortexed for the same, standardized amount of time (i.e., 2 minutes in total). A Neubauer counting chamber slide (with double chambers) was used to count sperm cells. An amount of $10 \mu \mathrm{l}$ of the solution was introduced into each of the two chambers. Counting of the sperm and calculating the total number of transferred sperm was performed according to the protocol (Nakadera et al., 2014).

Sperm counts were not normally distributed, so we analysed the data nonparametrically, using JMP 9 (SAS, Cary, NC, USA), with a Wilcoxon Signed Rank test to test for overall significance between the groups. This was followed by a Wilcoxon Pairwise Comparison to compare between the seven different time points. Finally, three additional Kruskal-Wallis tests were performed to rule out possible confounding factors (time until copulation, shell length, and shell length difference within pairs).

\section{Literature review}

For the literature review part of this study, we used Web of Science, searching for the terms 'sperm transfer' and 'copulation duration' and their combinations, with no date restrictions. Of each of the 218 resulting studies, we evaluated whether it 
indeed reported a relationship between copulation duration and number of transferred sperm. We only included papers in our final selection when the authors had indeed tested for the relationship between the number of sperm transferred and copulation duration. In cases where the found paper referred to another paper for this relationship, we verified whether that reference was already in our selected list and if not, the latter was included. For each paper that conformed to these criteria, we noted the species name, whether a relationship between copulation duration and the number of transferred sperm was found and, if so, the type of correlation reported (positively/negatively linear, asymptotic, exponential, S-curve), plus the underlying reason provided by the authors for this relationship.

\section{Results}

\section{Sperm transfer experiment}

Of the 220 pairs, we obtained samples from 71 inseminated snails; the remaining 149 pairs did not copulate within the set 6 h observation time. As a result, the sample size was 10 for each time point, except for the 30 min time point for which we obtained 11 samples. Very few of the samples of the time points 5 to 25 min contained sperm cells ( $5 \mathrm{~min}$, none; 10 to $25 \mathrm{~min}$, each contained one sperm-containing sample), while those of the $30 \mathrm{~min}$ time point and completed transfer contained sperm counts of 8 out of 10 and 9 out of 11 samples, respectively. The completed matings lasted $40.1 \pm 14.8 \mathrm{~min}$ on average.

Between the randomly assigned groups, we found no differences in the time until copulation started (Kruskal-Wallis: $H=1.604 \mathrm{df}=6, P=0.952$ ) or shell length (Kruskal-Wallis: $H=11.569, \mathrm{df}=6, P=0.072$ ). Finally, the shell length difference within the size-matched pairs, which was $0.018 \pm 0.042 \mathrm{~cm}$, did not differ significantly between time points (Kruskal-Wallis: $H=8.003$, df $=6, P=$ 0.238 ).

The number of transferred sperm cells differed significantly between groups (Wilcoxon: $\chi_{6}^{2}=45.278, P<0.001$ ). Pairwise post-hoc comparisons showed that the number of transferred sperm cells was significantly higher for the last two time points (30 minutes and complete transfer) compared to the five earlier time points (5-25 minutes; Wilcoxon Paired Comparisons: $P<0.05$; fig. 1). The 30 min treatment did not differ significantly from the completed transfer (fig. 1).

\section{Literature review}

We identified 57 relevant studies, including the result presented above. These turned out to be divided rather unequally over five animal groups: insects (42), spiders (6), gastropods (5), reptiles (3) and crustaceans (1). We will briefly explain our findings per animal group and also present these in a large overview (table 1).

For the insects, 39 of the 46 insect species were found to have a correlation between the number of sperm transferred and their copulation duration (table 1). 


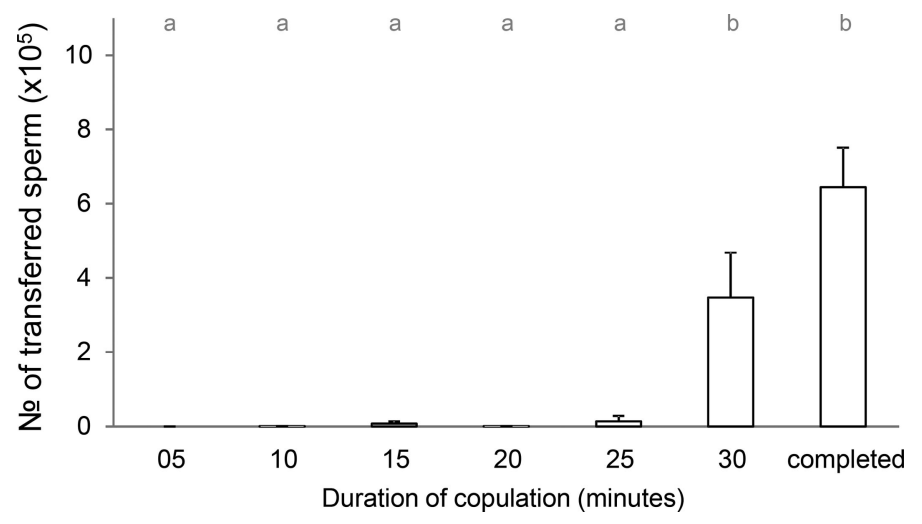

Figure 1. Relationship between the duration of copulation and the number of sperm cells transferred during interrupted and completed insemination. Significant differences are indicated with different, grey letters (Wilcoxon Paired Comparisons: $P<0.05$ ); error bars indicate standard errors.

The types of relationships ranged from positively linear ( 9 species), asymptotic (18), to unclear or non-determined (11) as well as negatively linear (1). For the remaining four insect species the reason remains unclear. If more than one reason for the relationship was offered, only the one that was deemed most probable by the authors was reported in table 1.

Five out of six papers regarding spiders showed a positive correlation between the number of sperm transferred and the copulation duration (table 1). Of the five spider species, three had a linear correlation, one had an exponential correlation and one had an unclear relationship. Successful mating was the most prevalent reason offered for the reported relationship ( 3 species), while presenting a nuptial gift was given as the reason for one species. For one species the reason remained unclear.

Three of the five gastropod species showed a positive relationship between the number of sperm transferred and the copulation duration (table 1). One correlation was linear, one asymptotic, and one an S-curve (see data reported above). One of the reasons offered to explain the relationship was successful mating (adequate sperm transfer), the other reason remained unclear.

In the three reptile species, only one was found to have a positive correlation between the number of sperm transferred and the copulation duration (table 1). The correlation was linear, and the underlying reason was successful mating.

For crustaceans, only one paper was found (table 1). In that species, the correlation between the number of sperm transferred and the copulation duration was positively linear and seemed to be driven by successful mating.

\section{Discussion}

With the dual aim of this paper, we demonstrate two things. First, our experimental data reveal that the sperm transfer process of the freshwater snail Lymnaea stagnalis is not linear, but that the sperm are only transferred near the end of copulation. 


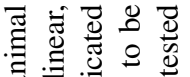
a.

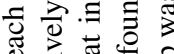

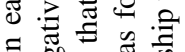

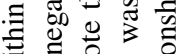
उ文之 글

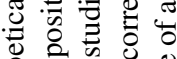

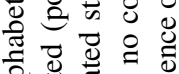

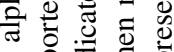
웡.引 으의 क力 ए⿹

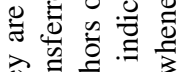

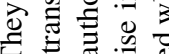
ำ 을 言额要

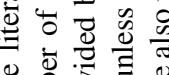

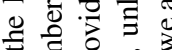
言完。 卷完语离言

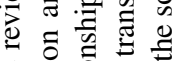
웜을 흔 훈

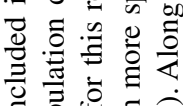
产

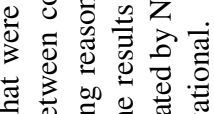

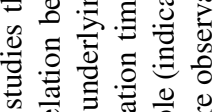

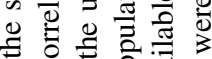

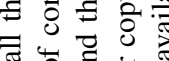

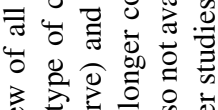

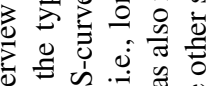

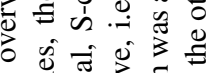

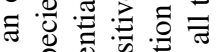
के क्ष

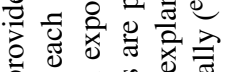

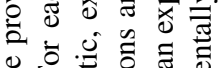

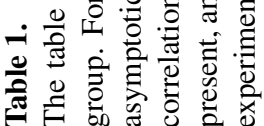

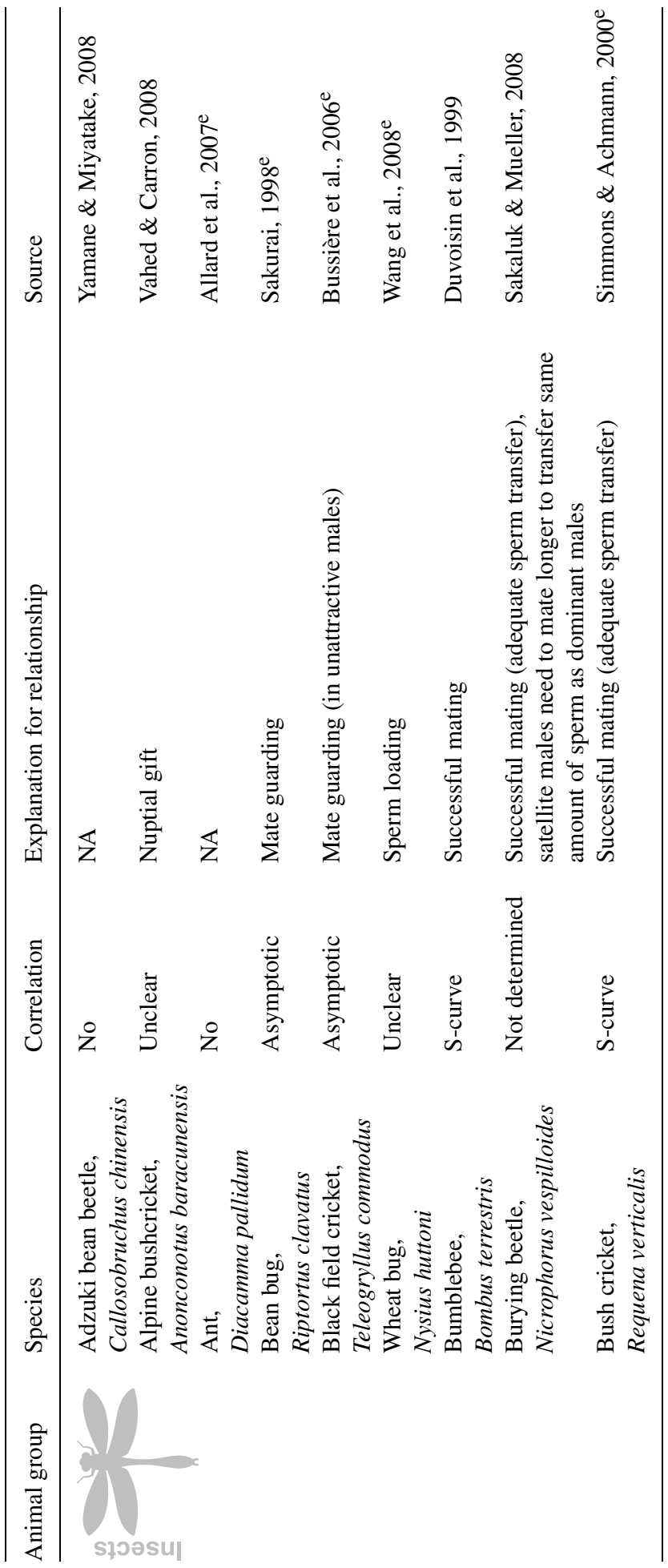


T.A. Weggelaar et al. / Animal Biology 69 (2019) 95-115

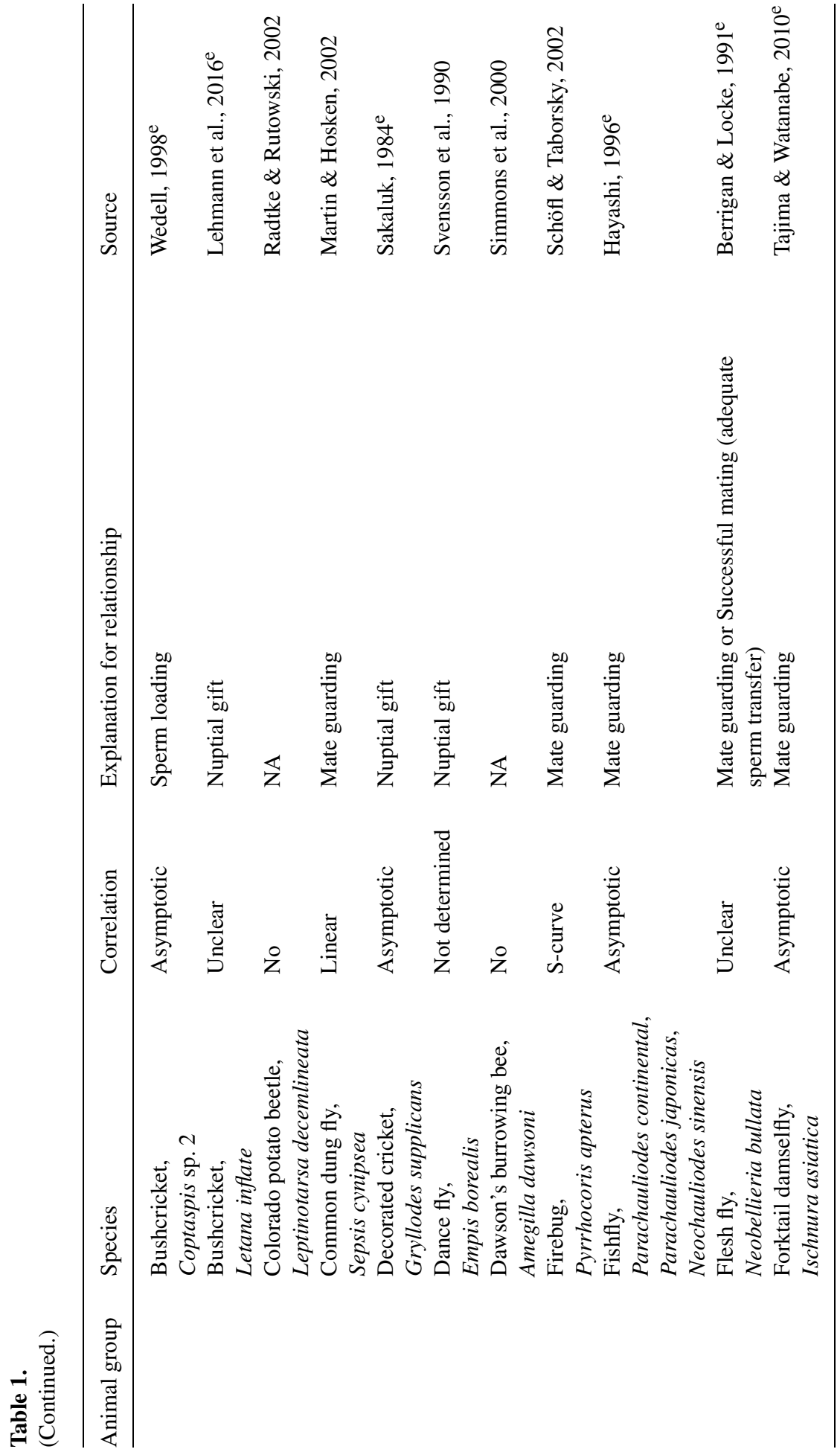




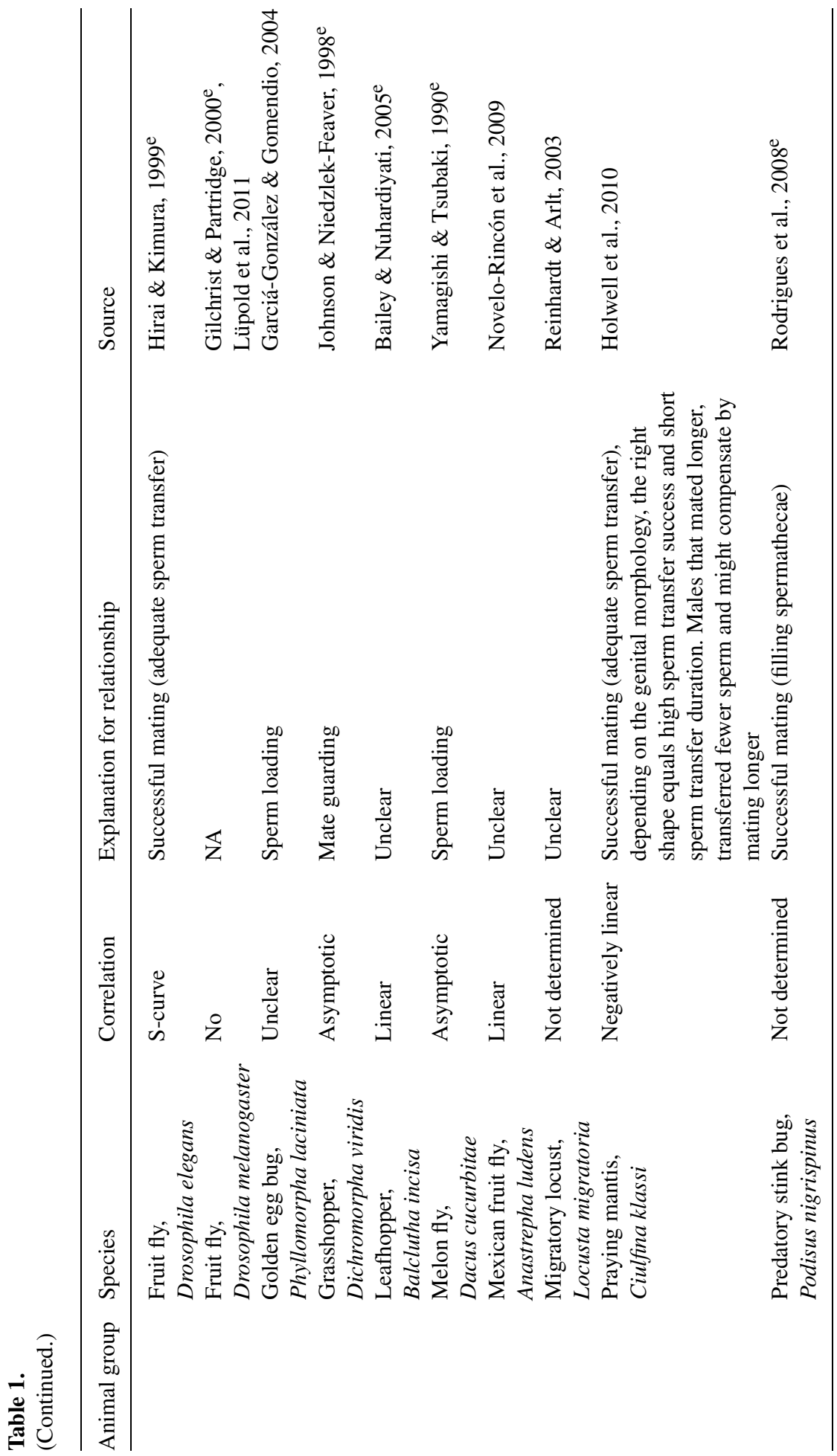


T.A. Weggelaar et al. / Animal Biology 69 (2019) 95-115

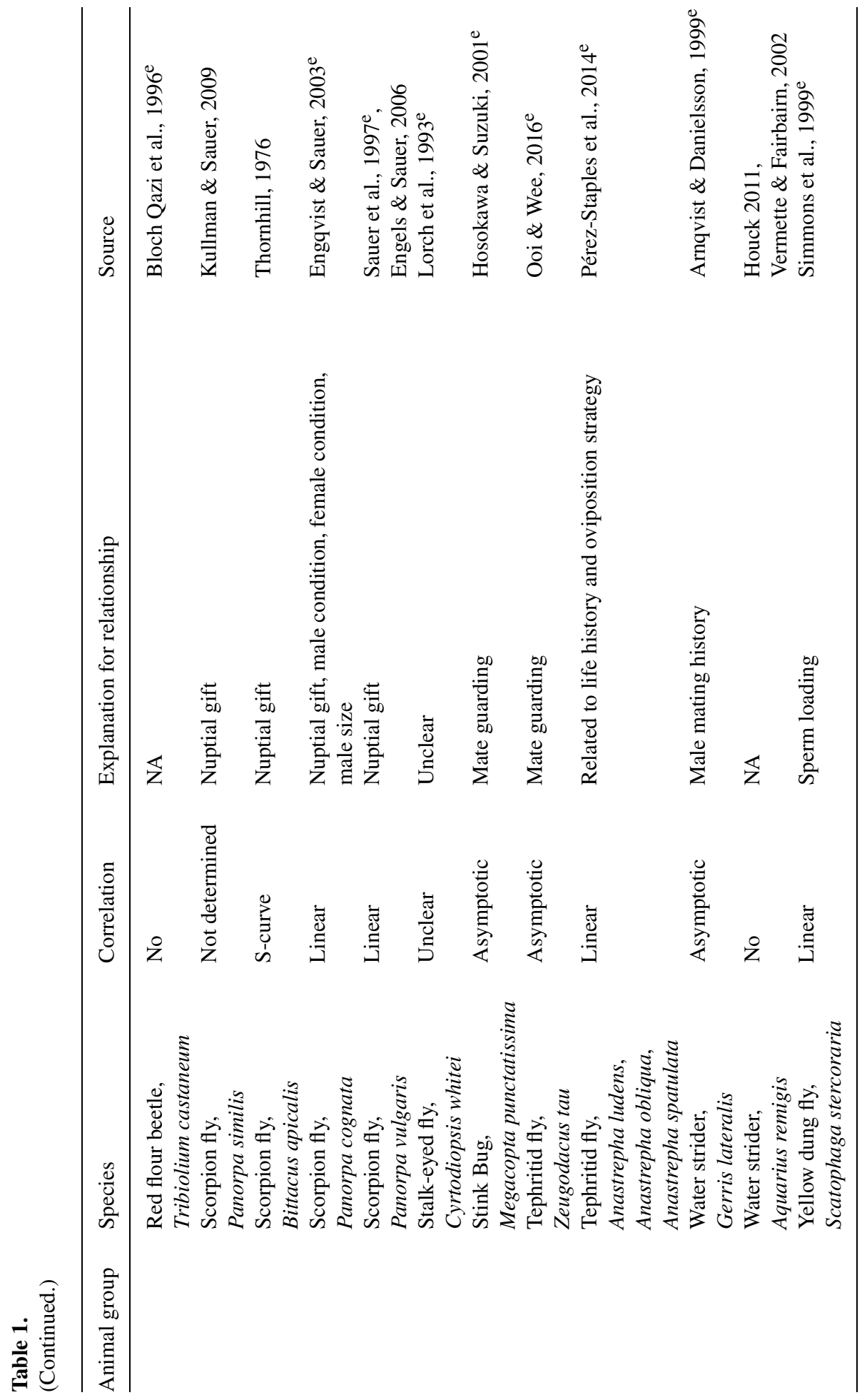




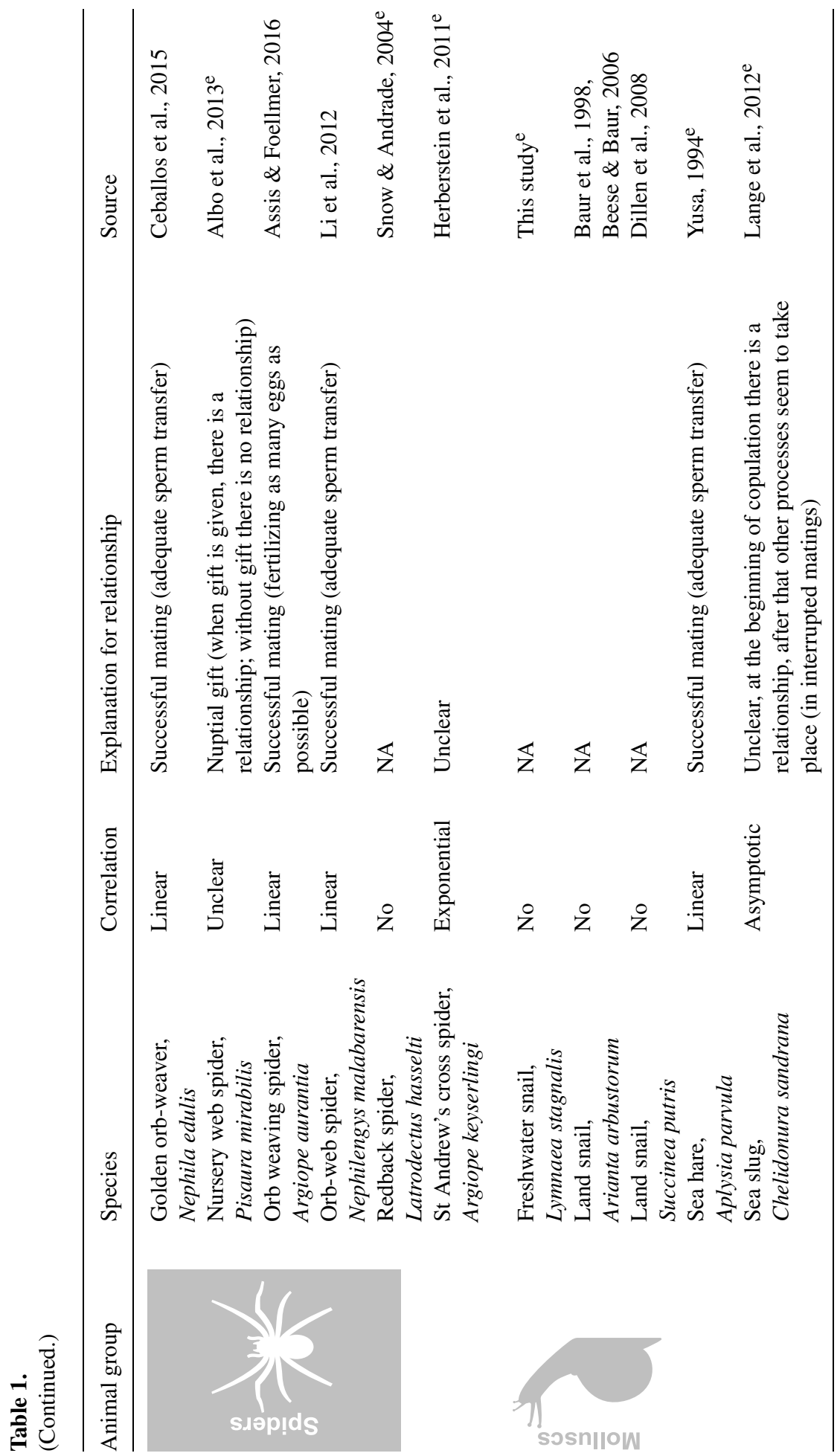




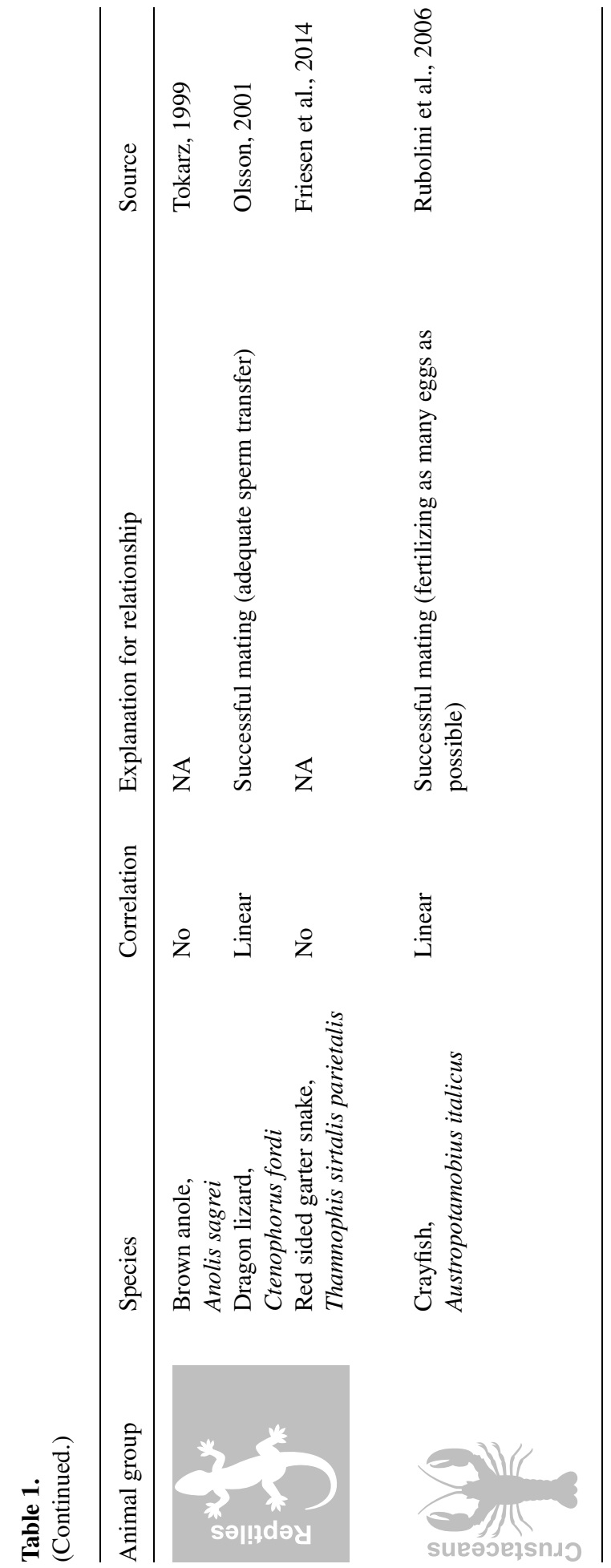


Second, our literature review shows that for many species copulation duration is not necessarily a proper proxy for the number of sperm that are transferred during copulation. In the following, we will elaborate on both of these conclusions in that order, and subsequently provide an overview of how to interpret sperm count data when these are obtained from natural and/or interrupted copulations.

The experiment that we performed with Lymnaea stagnalis was aimed at interpreting a specific discrepancy between previous findings on sperm counts in this species. Observational data indicated that the vas deferens, which transports the ejaculate to the penis and can be seen through the partly-opaque penis-carrying preputium, shows continuous peristalsis during copulation (Van Duivenboden \& Ter Maat, 1988). This would suggest a constant transport of the ejaculate to the partner during copulation. Nevertheless, another experimental study found that longer copulations did not result in more sperm transfer (Koene et al., 2008). Our data now show that, while ejaculate may be transported continuously towards the penis during copulation, the sperm are not transferred until copulation nears its end (after $30 \mathrm{~min}$ ).

One way of interpreting these data is that the whole ejaculate -i.e., sperm from the seminal vesicles and accessory gland proteins from the prostate gland (Jarne et al., 2010) - is being transported towards the penis and accumulates there until transfer. This would then require a mechanism for sensing when enough ejaculate has accumulated. As it happens, there are peripheral neurons present at the tip of the preputium that could serve such a function. Some of these neurons form varicosities on local musculature (and contain peptides such as APGW, pedal peptide, and/or LIP that are involved in the regulation of the male behaviour: De Lange and Van Minnen, 1998; Koene, 2010), so it is not unthinkable that they control the release of the ejaculate at the appropriate time. Clearly, this hypothesis warrants physiological follow-up experiments.

Another way of interpreting the presented data is that the transfer of sperm from the seminal vesicles and accessory gland proteins from the prostate gland does not occur at the same time. In other words, the undulations of the vas deferens may reflect the transfer of accessory gland proteins (which we did not measure here). If sperm are only transferred after some of these proteins have been transferred, near the end of copulation, this would also explain the sperm transfer pattern that we find here. In order to follow this hypothesis up properly, we need an effective method for location-tracking and quantifying both accessory gland proteins and sperm cells. Information about when accessory gland proteins are transferred in relation to sperm could also further elucidate their potential roles in the reproductive process. A few functions have been identified so far (Koene et al., 2010; Nakadera et al., 2014), but there are likely more. If these proteins are transferred prior to the sperm, this might mean that they set some female physiological process(es) in motion before the sperm arrive (thus resembling the hypodermic injection of accessory gland proteins prior to sperm transfer: Zizzari et al., 2014). This would also provide an explanation for why copulation needs to last so long if sperm can be 
transferred in a matter of minutes. Hence, the baseline information about the sperm transfer process documented by our experiment provides ample opportunities for interesting follow-up research.

Some of these hypotheses are indeed not farfetched. As it turns out, even for species with much shorter copulation times, this duration is often much longer than what is needed for sperm transfer. For example, the male fruit fly Drosophila melanogaster Meigen, 1830 needs eight minutes to transfer sperm; nevertheless, the male stays in copula with the female for more than twice that time, in this case to prevent the female from remating (Gilchrist \& Partridge, 1999). Likewise, in some bumblebees sperm transfer takes place in the first two minutes of copulation but copulation continues for up to 80 minutes, to ensure that the sperm enter the spermathecae (Duvoisin et al., 1999).

While reviewing the literature, it becomes obvious that there is enormous variation among species in their length of copulation. The shortest copulations last only seconds (e.g., in mosquitoes), and the longest up to 79 days (in certain stick insect species; Sivinski, 1978). Despite this huge divergence, our literature review clearly shows that the majority of this type of knowledge about the sperm transfer process is restricted to insects (42 of the 57 studies, including a total of 46 insect species). A positive relationship between copulation duration and number of sperm transferred was found most often in insects (table 1). Nevertheless, for each of the other animal groups for which we found literature this relationship was also found to be present at least once (table 1). Finally, in many of the reported studies, the general or specific circumstances under which this relationship occurs are often not entirely known, but mate guarding and nuptial gifts are present relatively often when a significant relationship is reported. Obviously, a significant number of animal groups is missing, which may be due to difficulties in measuring such a relationship. Nevertheless, it seems worthwhile to make that effort to obtain a better overview of how this relationship is distributed throughout internal fertilisers in the rest of the animal kingdom (such as birds, mammals, cetaceans, etc.).

It is now worth considering what the positive relationship, and its particular statistical shape, actually tells us. As noted in the results, the relationships can be divided into linear, asymptotic, exponential and S-curve descriptions (fig. 2). With this categorisation, one has to keep in mind that this is a statistical representation of the actual data, which is in turn influenced by the variance in copulation duration that was measured. From a biological perspective, the number of sperm transferred can be expected to increase with copulation duration up to a certain maximum (asymptote) where either the male runs out of sperm or the female reproductive tract is maximally filled (which is why all the relationships in fig. 2 reach a maximum at some point in time). These physical maxima are important, because they put exponential sperm transfer into a different light, meaning that at some point in time either the males of such a species must reach their maximum where they cannot transfer any more sperm or the females run out of space for receiving more sperm (represented by the unshaded time window of figs 2D and E). Hence, when sperm 

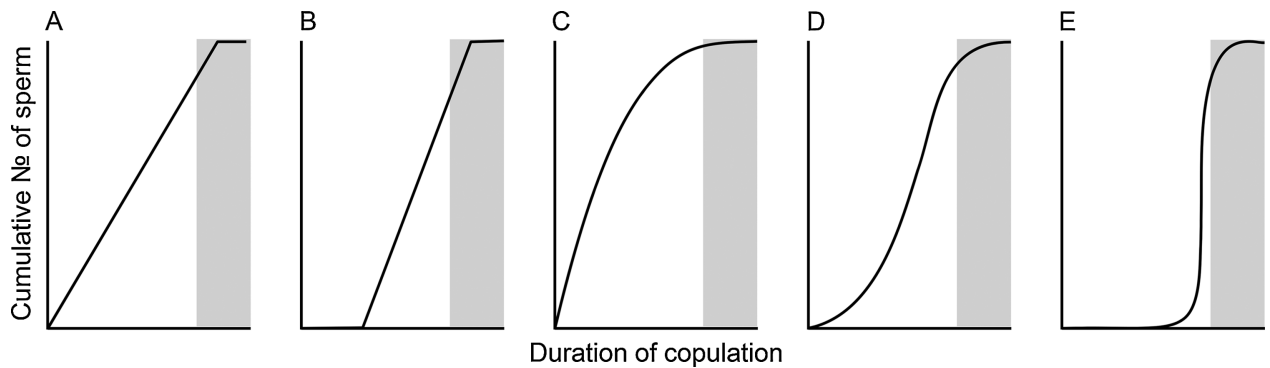

Figure 2. Graphical visualisation of the different relationships that are generally described for copulation duration and number of sperm transferred. As can be clearly seen, a linear (A and B) or exponential (D or E) line probably implies that the maximum has not yet been reached, which is indicated by their continuation into the shaded area of the graph, which represent the time points that cannot be measured if copulation always ends before the maximum is reached. It should also be noted that some of the lines essentially only differ from each other because sperm transfer does not start at time point zero (for example, compare $\mathrm{C}$ with $\mathrm{D}$ ). Moreover, the end of the graph need not indicate the end of copulation. After all, as explained in the text, some species remain in copula long after sperm have been transferred. Finally, the steepness of the curve is indicative of whether sperm is transferred gradually over time or only within a very short time window.

transfer is described to be exponential, or linear (the unshaded time window of figs $2 \mathrm{~A}$ and $\mathrm{B}$ ), this most likely means that the maximum number of transferred sperm is normally not reached in that species (either because the males needs to save sperm for a next mating or the female does not want to receive more). The latter also helps in interpreting whether a particular mating strategy, like the use of a nuptial gift or mate guarding to extend copulation, reaches its full potential in the species under study (i.e., sperm transfer reaches its maximum and thus enters the shaded area on the graphs of fig. 2). If not, either the males could be doing better by, for example, providing larger and/or more time-consuming gifts or guarding the mate for longer, or the females are in control of the duration of copulation, notwithstanding such male strategies.

To conclude, by combining an experiment with a literature review, we here demonstrate two things. The experimental work illustrates that even though copulation takes half an hour on average in the pond snail Lymnaea stagnalis, the transfer of sperm into the reproductive tract of the recipient only takes place at the very end of this period. This finding provides an explanation for why no correlation had been found previously between copulation duration and the amount of sperm transferred (and opens up some interesting new issues to address, see above). By also reviewing the literature, we illustrate that the seemingly intuitive (linear) correlation between copulation duration and sperm transfer is not ubiquitous, but that there are various non-linear relationships possible and that these can even differ drastically between closely related species. Hence, before assuming that insemination or copulation duration is a good proxy for sperm transfer in any species, one really needs to establish this by providing experimental evidence and taking into account (when describing 
the process) that whenever studying such processes there will be an upper limit, either on the male or female side, even when this cannot be measured directly.

\section{Acknowledgements}

We would like to thank the guest editor of this special issue, Dr. Z. Valentina Zizzari, for encouraging us to contribute and the anonymous reviewers for their critical, yet constructive, comments.

\section{References}

Albo, M.J., Bilde, T. \& Uhl, G. (2013) Sperm storage mediated by cryptic female choice for nuptial gifts. Proc. Biol. Sci., 280, 20131735.

Allard, D., Gobin, B. \& Billen, J. (2007) Timing of sperm transfer in Diacamma pallidum. Physiol. Entomol., 32, 382-387.

Alvarez, B. \& Koene, J.M. (2019) Sexual conflict in nonhumans. In: T.K. Shackelford \& V. WeekesShackelford (Eds) Encyclopedia of Evolutionary Psychological Science. Springer International Publishing, Cham, Switzerland.

Arnqvist, G. \& Danielsson, I. (1999) Postmating sexual selection: the effects of male body size and recovery period on paternity and egg production rate in a water strider. Behav. Ecol., 10, 358-365.

Assis, B.A. \& Foellmer, M.W. (2016) One size fits all? Determinants of sperm transfer in highly dimorphic orb-web spider. J. Evol. Biol., 29, 1106-1120.

Bailey, W.J. \& Nuhardiyati, M. (2005) Copulation, the dynamics of sperm transfer and female refractoriness in the leafhopper Balclutha incise (Hemiptera: Cicadellidae: Deltocephalinae). Physiol. Entomol., 30, 343-352.

Bateman, A. (1948) Intra-sexual selection in Drosophila. Heredity, 2, 349-368.

Baur, B., Locher, R. \& Baur, A. (1998) Sperm allocation in the simultaneously hermaphroditic land snail Arianta arbustorum. Anim. Behav., 56, 839-845.

Beese, K. \& Baur, B. (2006) Expandable spermatheca influences sperm storage in the simultaneously hermaphroditic snail Arianta arbustorum. Invertebr. Reprod. Dev., 49, 93-101.

Berrigan, D. \& Locke, S.J. (1991) Body size and male reproductive performance in the flesh fly, Neobellieria bullata. J. Insect Physiol., 37, 575-581.

Birkhead, T.R. \& Møller, A.P. (1992) Sperm Competition in Birds. Evolutionary Causes and Consequences. Academic Press, San Diego, CA, USA.

Birkhead, T.R., Hosken, D.J. \& Pitnick, S. (2009) Sperm Biology: an Evolutionary Perspective. Elsevier, Amsterdam, The Netherlands.

Bloch Qazi, M.C., Herbeck, J.T. \& Lewis, S.M. (1996) Mechanisms of sperm transfer and storage in the red flour beetle (Coleoptera: Tenebrionidae). Ann. Entomol. Soc. Am., 89, 892-897.

Brown, M.J.F. \& Baer, B. (2005) The evolutionary significance of long copulation duration in bumble bees. Apidologie, 36, 157-167.

Bussière, L.F., Hunt, J., Jennions, M.D. \& Brooks, R. (2006) Sexual conflict and cryptic female choice in the black field cricket, Teleogryllus commodus. Evolution, 60, 792-800.

Ceballos, L., Jones, T.M. \& Elgar, M.A. (2015) Patterns of sperm transfer in the golden orb-weaver Nephila edulis. Ethology, 121, 617-624.

Cordero-Rivera, A. (2016) Sperm removal during copulation confirmed in the oldest extant damselfly, Hemiphlebia mirabilis. PeerJ, 4, e2077. DOI:10.7717/peerj.2077. 
Darwin, C. (1871) The Descent of Man, and Selection in Relation to Sex. Murray, London, UK.

De Boer, P.A.C.M., Jansen, R.F., Koene, J.M. \& Ter Maat, A. (1997) Nervous control of male sexual drive in the hermaphroditic snail Lymnaea stagnalis. J. Exp. Biol., 200, 941-951.

De Lange, R.P.J. \& Van Minnen, J. (1998) Localization of the neuropeptide APGWamide in gastropod molluscs by in situ hybridization and immunocytochemistry. Gen. Comp. Endocrinol., 109, 166174.

Dillen, L., Jordaens, K., Dielemen, W. \& Backeljau, T. (2008) Effects of isolation and body size on the mating behaviour of the hermaphroditic land snail Succinea putris. Anim. Behav., 75, 1401-1411.

Duvoisin, N., Baer, B. \& Schmid-Hempel, P. (1999) Sperm transfer and male competition in a bumblebee. Anim. Behav., 58, 743-749.

Eady, P.E. \& Brown, D.V. (2017) Male-female interactions drive the (un)repeatability of copula duration in an insect. $R$. Soc. Open Sci., 4, 160962. DOI:10.1098/rsos.160962.

Eberhard, W.G. (1996) Female Control: Sexual Selection by Cryptic Female Choice. Princeton University Press, Princeton, NJ, USA.

Engels, S. \& Sauer, K.P. (2006) Love for sale and its fitness benefits: nuptial gifts in the scorpionfly Panorpa vulgaris represent paternal investment. Behaviour, 143, 825-837.

Engqvist, L. \& Sauer, K.P. (2003) Determinants of sperm transfer in the scorpionfly Panorpa cognate: male variation, female condition and copulation duration. J. Evol. Biol., 16, 1196-1204.

Friesen, C.R., Squire, M.K. \& Mason, R.T. (2014) Intrapopulational variation of ejaculate traits and sperm depletion in red-sided garter snakes. J. Zool., 292, 192-201.

García-González, F. \& Gomendio, M. (2004) Adjustment of copula duration and ejaculation size according to the risk of sperm competition in the golden egg bug (Phyllomorpha laciniata). Behav. Ecol., 15, 23-30.

Gilchrist, A.S. \& Partridge, L. (2000) Why is it difficult to model sperm displacement in Drosophila melanogaster: the relation between sperm transfer and copulation duration. Evolution, 54, 534542.

Hayashi, F. (1996) Insemination through an external attached spermatophore: bundled sperm and postcopulatory mate guarding by male fishflies (Megaloptera: Corydalidae). J. Insect Physiol., 42, 859-866.

Herberstein, M.E., Schneider, J.M., Harmer, A.M.T., Gaskett, A.C., Robinson, K., Shaddick, K., Soetkamp, D., Wilson, P.D., Pekár, S. \& Elgar, M.A. (2011) Sperm storage and copulation duration in a sexually cannibalistic spider. J. Ethol., 29, 9-15.

Hirai, Y. \& Kimura, M.T. (1999) Effects of copulation duration on fertility and sexual receptivity of females in Drosophila elegans. Zool. Sci., 16, 417-421.

Holwell, G.I., Winnick, C., Tregenza, T. \& Herberstein, M.E. (2010) Genital shape correlates with sperm transfer success in the praying mantis Ciulfina klassi (Insecta: Mantodea). Behav. Ecol. Sociobiol., 64, 617-625.

Hosokawa, T. \& Suzuki, N. (2001) Significance of prolonged copulation under the restriction of daily reproductive time in the stink bug Megacopta punctatissima (Heteroptera: Plataspidae). Ann. Entomol. Soc. Am., 94, 750-754.

Houck, C.J. (2011) The effect of sex ratio on copulation, sperm transfer, and sperm reserves in the waterstrider, Aquarius remigis. UC Riverside. ProQuest ID: Houck_ucr_0032N_10763. Merritt ID: ark:/13030/m5377cm0. Available from https://escholarship.org/uc/item/16k330gh.

Jarne, P., David, P., Pointier, J.-P. \& Koene, J.M. (2010) Basommatophoran gastropods. In: A. Córdoba-Aguilar \& J.L. Leonard (Eds) The Evolution of Primary Sexual Characters in Animals, pp. 173-196. Oxford University Press, Oxford, UK. 
Johnson, J.A. \& Niedzlek-Feaver, M. (1998) A histological study of copulation duration, patterns of sperm transfer and organization inside the spermatheca of a grasshopper, Dichromorpha viridis (scudder). J. Orthopaed. Res., 7, 139-146.

Kelly, C.D. \& Jennions, M.D. (2011) Sexual selection and sperm quantity: meta-analyses of strategic ejaculation. Biol. Rev., 86, 863-884.

Koene, J.M. (2010) Neuro-endocrine control of reproduction in hermaphroditic freshwater snails: mechanisms and evolution. Front. Behav. Neurosci., 4, 167.

Koene, J.M. (2017) Sex determination and gender expression: reproductive investment in snails. Mol. Reprod. Dev., 84, 132-143.

Koene, J.M., Montagne-Wajer, K. \& Ter Maat, A. (2007) Aspects of body size and mate choice in the simultaneously hermaphroditic pond snail Lymnaea stagnalis. Anim. Biol., 57, 247-259.

Koene, J.M., Loose, M.J. \& Wolters, L. (2008) Mate choice is not affected by mating history in the simultaneously hermaphroditic snail Lymnaea stagnalis. J. Mollusc. Stud., 74, 331-335.

Koene, J.M., Sloot, W., Montagne-Wajer, K., Cummins, S.F., Degnan, B.M., Smith, J.S., Nagle, G.T. \& Ter Maat, A. (2010) Male accessory gland protein reduces egg laying in a simultaneous hermaphrodite. PLoS One, 5, e10117. DOI:10.1371/journal.pone.0010117.

Kullmann, H. \& Sauer, K.P. (2009) Mating tactic dependent sperm transfer rates in Panorpa similis (Mecoptera; Panorpidae): a case of female control? Ecol. Entomol., 34, 153-157.

Lange, R., Beninde, J., Reichel, V., Werminghausen, J., Gerlach, T. \& Anthes, N. (2012) Copulation duration does not predict sperm transfer in a marine hermaphrodite. Anim. Behav., 83, 469-472.

Lehmann, G.U.C., Heller, K. \& Mai, R. (2016) Prolonged copulations as an alternative to male nuptial gift investment in the bushcricket Letana inflate (Orthoptera: Tettigoniidae). J. Ethol., 34, 191-194.

Li, D., Oh, J., Kralj-Fišer, S. \& Kuntner, M. (2012) Remote copulation: male adaptation to female cannibalism. Biol. Lett., 8, 512-515.

Lodi, M. \& Koene, J.M. (2017) Hidden female physiological resistance to male accessory gland substances in a simultaneous hermaphrodite. J. Exp. Biol., 220, 1026-1031.

Loose, M.J. \& Koene, J.M. (2008) Sperm transfer is affected by mating history in the simultaneously hermaphroditic snail Lymnaea stagnalis. Invert. Biol., 127, 162-167.

Lorch, P.D., Wilkinson, G.S. \& Reillo, P.R. (1993) Copulation duration and sperm precedence in the stalk-eyed fly Cyrtodiopsis whitei (Diptera: Diopsidae). Behav. Ecol. Sociobiol., 32, 303-311.

Lüpold, S., Manier, M.K., Ala-Honkola, O., Belote, J.M. \& Pitnick, S. (2011) Male Drosophila melanogaster adjust ejaculate size based on female mating status, fecundity, and age. Behav. Ecol., 22, 184-191.

Magalhaes, I.S., Smith, A.M. \& Joyce, D.A. (2017) Quantifying mating success of territorial males and sneakers in a bower-building cichlid fish. Sci. Rep., 7, 41128. DOI:10.1038/srep41128.

Martin, O.Y. \& Hosken, D.J. (2002) Strategic ejaculation in the common dung fly Sepsis cynipsea. Anim. Behav., 63, 541-546.

McCullough, E.L., Buzatto, B.A. \& Simmons, L.W. (2018) Population density mediates the interaction between pre- and postmating sexual selection. Evolution, 72, 893-905.

Nakadera, Y., Swart, E.M., Hoffer, J.N.A.H., Den Boon, O., Ellers, J. \& Koene, J.M. (2014) Receipt of seminal fluid proteins causes reduction of male investment in a simultaneous hermaphrodite. Curr. Biol., 24, 859-862.

Novelo-Rincón, L.F., Montoya, P., Hernández-Ortiz, V., Liedo, P. \& Tolefo, J. (2009) Mating performance of sterile Mexican fruit fly Anastrepha ludens (Dipt., Tephritidae) male used as vectors of Beauveria bassiana (Bals.) Vuill. J. Appl. Entomol., 133, 702-710.

Olsson, M. (2001) 'Voyeurism' prolongs copulation duration in the dragon lizard Ctenophorus fordi. Behav. Ecol. Sociobiol., 50, 378-381. 
Ooi, Y.T. \& Wee, S.L. (2016) Sexual maturation, mating propensity and remating incidence of Zeugodacus tau (Walker) (Diptera: Tephritidae). J. Asia Pac. Entomol., 19, 451-457.

Parker, G.A. (1970) Sperm competition and its evolutionary consequences in the insects. Biol. Rev., 45, 525-567.

Parker, G.A. \& Pizzari, T. (2010) Sperm competition and ejaculate economics. Biol. Rev., 85, 897-934.

Pérez-Staples, D., Córdova-García, G. \& Aluja, M. (2014) Sperm dynamics and cryptic male choice in tephritid flies. Anim. Behav., 89, 131-139.

Radtke, M.G. \& Rutowski, R.L. (2002) Variation in the number of sperm transferred during mating among males of the Colorado potato beetle (Coleoptera: Chrysomelidae). J. Insect Physiol., 48, 1087-1092.

Reinhardt, K. \& Arlt, D. (2003) Ejaculate size variation in the migratory locust, Locusta migratoria. Behaviour, 140, 319-332.

Rodrigues, A.R.S., Serrão, J.E., Teixeira, V.W., Torres, J.B. \& Teixeira, A.A. (2008) Spermatogenesis, changes in reproductive structures, and time constraint associated with insemination in Podisus nigrispinus. J. Insect Physiol., 54, 1543-1551.

Rubolini, D., Galeotti, P., Ferrari, G., Spairani, M., Bernini, F. \& Fasola, M. (2006) Sperm allocation in relation to male traits, female size and copulation behaviour in a freshwater crayfish species. Behav. Ecol. Sociobiol., 60, 212-219.

Sakaluk, S.K. (1984) Male crickets feed females to ensure complete sperm transfer. Science, 223, 609-610.

Sakaluk, S.K. \& Mueller, J.K. (2008) Risk of sperm competition mediates copulation duration, but not paternity, of male burying beetles. J. Insect Behav., 21, 153-163.

Sakurai, T. (1998) Receptivity of female remating and sperm number in the sperm storage organ in the bean bug, Riportus clavatus (Heteroptera: Alydidae). Res. Popul. Ecol. (Kyoto), 40, 167-172.

Sauer, K.P., Sindern, J. \& Kall, N. (1997) Nutritional status of males and sperm transfer in the scorpionfly Panorpa vulgaris (Mecoptera: Panorpidae). Entomol. Germ., 21, 189-204.

Schärer, L., Rowe, L. \& Arnqvist, G. (2012) Anisogamy, chance and the evolution of sex roles. Trends Ecol. Evol., 27, 260-264.

Schöfl, G. \& Taborsky, M. (2002) Prolonged tandem formation in firebugs (Pyrrhocoris apterus) serves mate-guarding. Behav. Ecol. Sociobiol., 52, 426-433.

Scholes, E. \& Laman, T.G. (2018) Distinctive courtship phenotype of the Vogelkop Superb Birdof-Paradise Lophorina niedda Mayr, 1930 confirms new species status. PeerJ, 6, e4621. DOI:10. 7717/peerj.4621.

Simmons, L.W. (2001) Sperm Competition and Its Evolutionary Consequences in the Insects. Princeton University Press, Woodstock, UK.

Simmons, L.W. \& Achmann, R. (2000) Microsatellite analysis of sperm-use patterns in the bushcricket Requena verticalis. Evolution, 54, 942-952.

Simmons, L.W., Parker, G.A. \& Stockley, P. (1999) Sperm displacement in the yellow dung fly, Scatophaga stercoraria: an investigation of male and female processes. Am Nat., 153, 302-314.

Simmons, L.W., Tomkins, J.L. \& Alcock, J. (2000) Can minor males of Dawson's burrowing bee, Amegilla dawsoni (Hymenoptera: Anthophorini) compensate for reduced access to virgin females through sperm competition? Behav. Ecol., 11, 319-325.

Sivinski, J. (1978) Intrasexual aggression in the stick insects Diapheromera veliei and D. covilleae and sexual dimorphism in the phasmatodea. Psyche, 85, 395-405.

Snow, L.S.E. \& Andrade, M.C.B. (2004) Pattern of sperm transfer in redback spiders: implications for sperm competition and male sacrifice. Behav. Ecol., 15, 785-792. 
Svensson, B.G., Petersson, E. \& Frisk, M. (1990) Nuptial gift size prolongs copulation duration in the dance fly Empis borealis. Ecol. Entomol., 15, 225-229.

Tajima, Y. \& Watanabe, M. (2010) Sperm transfer process in the non-territorial Ischnura asiatica (Brauer) during copulation (Zygoptera: Coenagrionidae). Odonatologica, 39, 253-258.

Ter Maat, A., Pieneman, A.W. \& Koene, J.M. (2012) The effect of light on induced egg laying in the simultaneous hermaphrodite Lymnaea stagnalis. J. Mollusc. Stud., 78, 262-267.

Thornhill, R. (1976) Sexual selection and nuptial feeding behaviour in Bittacus apicalis (Insecta: Mecoptera). Am. Nat., 110, 529-548.

Tokarz, R. (1999) Relationship between copulation duration and sperm transfer in the lizard Anolis sagrei. Herpetologica, 55, 234-241.

Vahed, K. \& Carron, G. (2008) Comparison of forced mating behaviour in four taxa of Anonconotus, the Alpine bushcricket. J. Zool., 276, 313-321.

Van Duivenboden, Y. \& Ter Maat, A. (1988) Mating behaviour of Lymnaea stagnalis. Malacologia, 28, 53-64.

Vermette, R. \& Fairbairn, D.J. (2002) How well do mating frequency and duration predict paternity success in the polygynandrous water strider Aquarius remigis? Evolution, 56, 1808-1820.

Wada, T., Takegaki, T., Mori, T. \& Natsukari, Y. (2010) Sperm removal, ejaculation and their behavioural interaction in male cuttlefish in response to female mating history. Anim. Behav., 79, 613-619.

Wang, Q., Yang, L. \& Hedderley, D. (2008) Function of prolonged copulation in Nysius huttoni white (Heteroptera: Lygaeidae) under male-biased sex ratio and high population density. J. Insect Behav., 21, 89-99.

Wedell, N. (1998) Sperm protection and mate assessment in the bushcricket Coptaspis sp. 2. Anim. Behav., 56, 357-363.

Wedell, N., Gage, M.J. \& Parker, G.A. (2002) Sperm competition, male prudence and sperm-limited females. Trends Ecol. Evol., 17, 313-320.

Yamagishi, M. \& Tsubaki, Y. (1990) Copulation duration and sperm transfer in the melon fly, Dacus cucurbitae Coquillett (Diptera, Tephritidae). Appl. Entomol. Zool., 4, 517-519.

Yamane, T. \& Miyatake, T. (2008) Strategic ejaculation and of polyandry in Callosobruchus chinensis (Coleoptera: Bruchidae). J. Ethol., 26, 225-231.

Yusa, Y. (1994) Factors regulating sperm transfer in a hermaphroditic sea hare, Aplysia parvula Mörch, 1863 (Gastropoda: Opisthobranchia). J. Exp. Mar. Biol. Ecol., 181, 213-221.

Zizzari, Z.V., Smolders, I. \& Koene, J.M. (2014) Alternative delivery of male accessory gland products. Front. Zoology, 11, 32. DOI:10.1186/1742-9994-11-32. 